\title{
P0602 - Plasma concentration of lectin complement pathway member MASP3 among T2DM patients during and after bacterial infection
}

\author{
L.J. Barkai ${ }^{1}$, E. Sipter ${ }^{1}$, D. Csuka ${ }^{1}$, Z. Prohaszka ${ }^{1}$, N. Hosszufalusi ${ }^{1}$ \\ ${ }^{1}$ Semmelweis University, 3rd Department of Internal Medicine, Budapest, Hungary.
}

\section{Background}

Bacterial infections among type $\mathbf{2}$ diabetes are more frequent and severe in comparison with non-diabetic patients. The background of this phenomenon is not fully understood, HbA1c and infection risk is not evidently associated.

The complement system plays an important role in response to pathogens (Fig. 1).

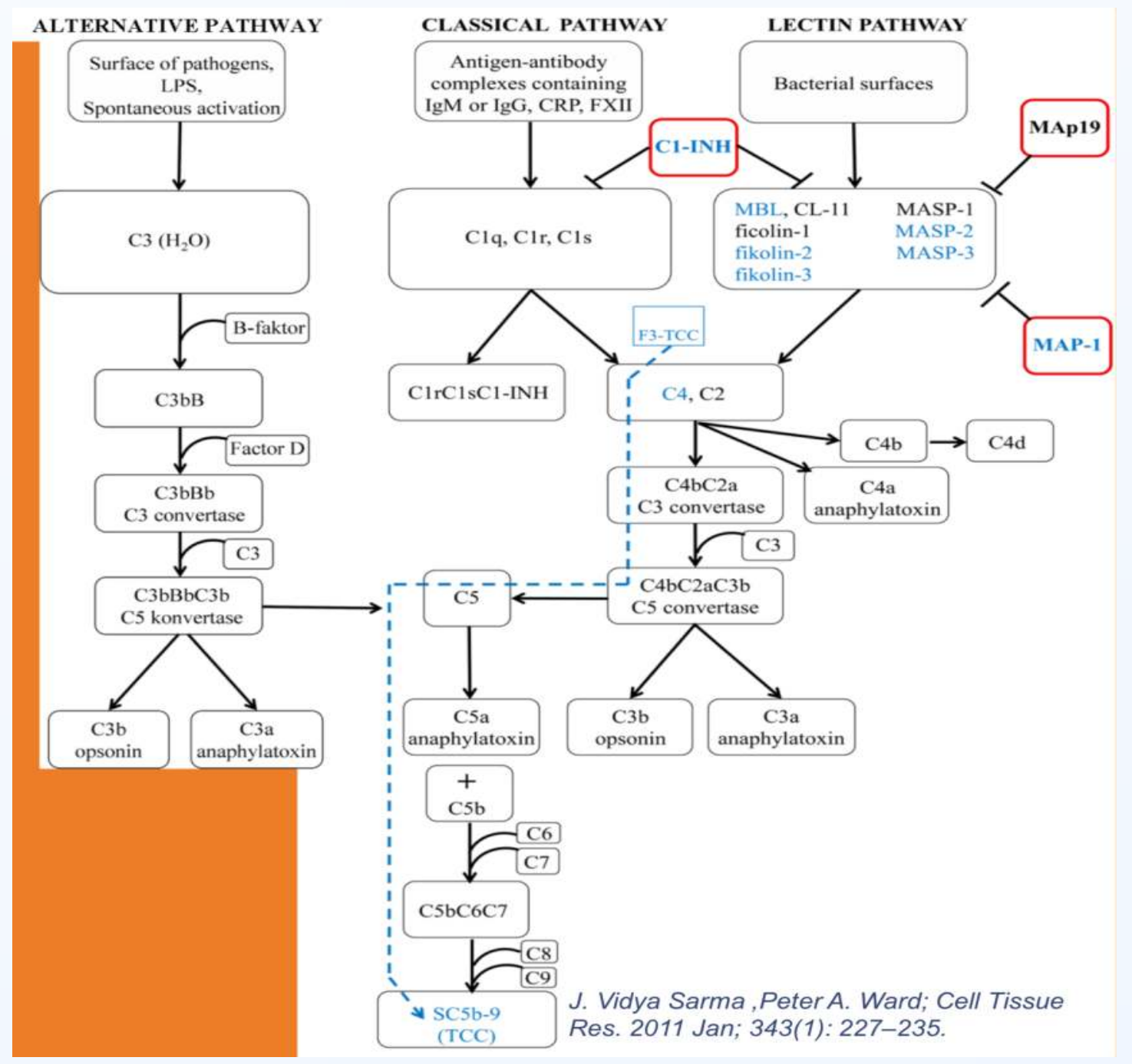

Fig.1: Activation of the complement system.

One of its three activation pathways is the lectin pathway, where members can bind to carbohydrate molecules on the surface of pathogens thus resulting in the activation of MBL- associated serine proteases (MASPs) (Fig. 2).

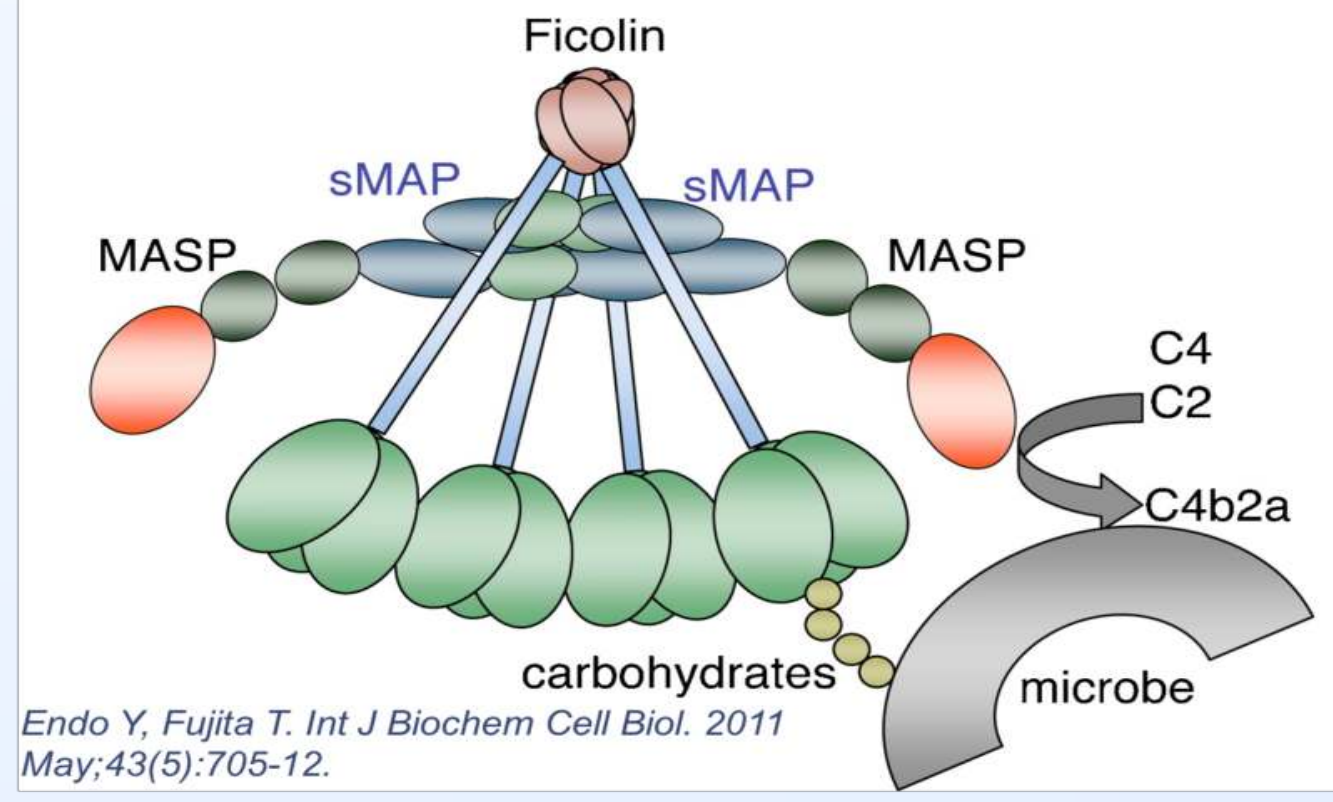

Fig.2: Activation of MASPS.

MASP2 with other members of the lectin pathway can form activator complexes, while MASP3 seems to have an inhibitory role on complement activation.

\section{Aims}

We hypothesize that glycated proteins in T2DM may serve as false recognition patterns which can lead to an altered complement activation.

The goal of our study was to describe a possible role of MASP2 and MASP3 on increased risk of bacterial infections among T2DM patients.

Supported by: EFSD New Horizons

Dr. Koranyi Andras Foundation

Copyright (C) 2017 Barkai LJ et al., barkai.lj@gmail.com

\section{Materials and methods}

Prospective study including patients with clinical diagnosis of acute community acquired bacterial infections with type 2 diabetes (T2DM) or without it (ND). Patients with immunological, hematological and oncological illnesses were excluded.

Plasma concentrations of MASP2 and MASP3 were measured using commercial ELISA kits.

Patients were reassessed for both complement and clinical laboratory parameters after a minimum of three-month infection-free period. Statistical analysis was performed using GraphPad Prism 5.

\section{Results and discussion}

Among the 205 T2DM and 199 ND patients hospitalized due to bacterial infections, parameters of 112 and 90 were reassessed, respectively (Table 1.).

\begin{tabular}{|c|c|c|}
\hline Table 1. Clinical parameters. & $\underline{\text { T2DM }}$ & $\underline{\text { ND }}$ \\
\hline Subjects (sex: M/F) & $\mathbf{2 0 5}(95 / 110)$ & $\mathbf{1 9 9}(96 / 103)$ \\
\hline $\begin{array}{c}\text { Subjects reassessed } \\
\text { (sex: M/F) }\end{array}$ & $\begin{array}{c}\mathbf{1 1 2} \\
(56 / 56)\end{array}$ & $\begin{array}{c}\mathbf{9 0} \\
(50 / 43)\end{array}$ \\
\hline $\begin{array}{c}\text { Age in years } \\
\text { median [25-75\% percentile] }\end{array}$ & $\begin{array}{c}\mathbf{7 2} \\
(65.0-80.0)\end{array}$ & $\begin{array}{c}\mathbf{7 2} \\
59.0-80.3)\end{array}$ \\
\hline $\begin{array}{c}\text { HbA1c on admission (\%) } \\
\text { median [25-75\% percentile] }\end{array}$ & $\begin{array}{c}\mathbf{7 . 4 5} \\
(6.4-8.7)\end{array}$ & $\begin{array}{c}\mathbf{5 . 6} \\
(5.3-6.0)\end{array}$ \\
\hline $\begin{array}{c}\text { Mortality counts - } \\
\text { during hospitalization }\end{array}$ & $\mathbf{2 1 / 2 0 5}$ & $\mathbf{2 0 / 1 9 9}$ \\
\hline
\end{tabular}

Concentrations of MASP2 were higher MASP3 were lower during infection, in both groups, compared to the infection-free period (p<0.0001, for both parameters in both groups) (Fig. 3).

Higher levels of MASP3 were found among T2DM patients compared to ND subjects in presence $(p=0.0083)$ and in absence $(p=0.0233)$ of the infection.

Conclusion: Though no mortality difference was observed between the two groups, our results show a possibly altered activation of the lectin complement pathway among T2DM patients.

Fig.3: MASP 3 and MASP2 concentrations.

MASP2 concentration (ng/ml)

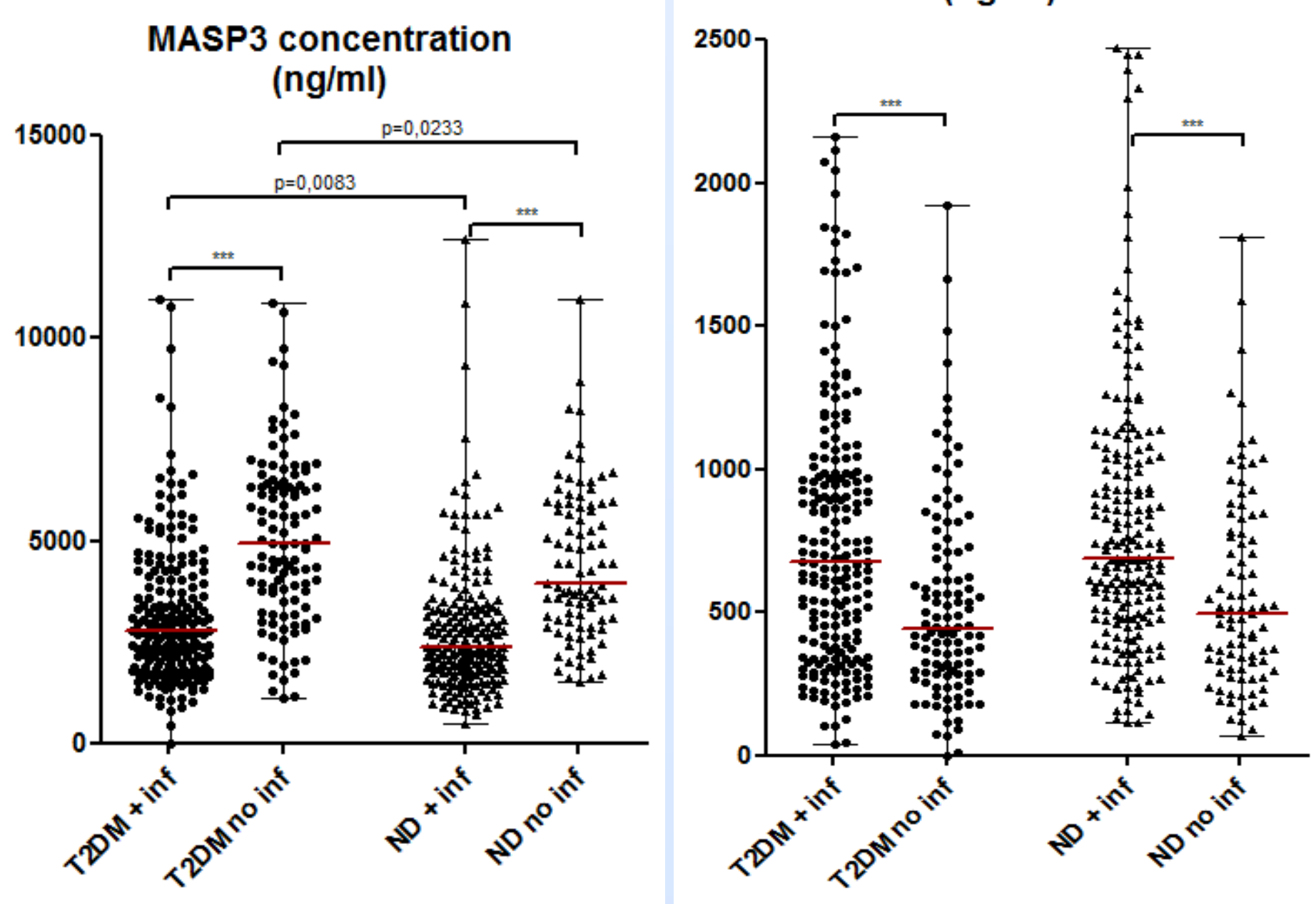

